\title{
Research on the Renovation of Old Industrial Buildings in China - - Take Haoke Industrial Park (Baoding, China) as an Example
}

\author{
Yi Jin \\ School of North China Electric Power University, Baoding 071000, China. \\ jeedith@126.com, 646925157@qq.com
}

\begin{abstract}
Keywords: Old industrial buildings; renovation; recycling; contemporary value; Haoke industrial park.
\end{abstract}

\begin{abstract}
With the rise of the tertiary industry and the adjustment of Chinese economic structure, a considerable amount of industrial buildings which have lost their original functions are left behind time. Their abandonment in the cities cause a huge waste of precious land resources. Instead of tearing down, more and more people begin to find the enormous social and economic benefits in renovating these old factory buildings. Actually, the renovation of these buildings possesses significant contemporary values. Old as it is, these abandoned factories carry cultural and historical values. What's more, its unique architectural style creates a new aesthetic notion "Industrial Aesthetics”. Apart from theoretical analysis, this article researches on the Haoke Park in Baoding, China, to see what the current situation is like in this renovation industry. This article manages to find the successful points of this area, despite a few failures needed to be improved.
\end{abstract}

\section{Background}

At the end of last century, lots of industrial buildings sprung up because of the economic structure of that time, which relies heavily on industry to boost domestic product. Last decades, China has stepped into an era where industry has no longer been the dominant industry. With the adjustment of industry, a considerable amount of old factories and industrial buildings are left behind by the era. These buildings are either abandoned or left idle in the city, which causes a large waste of land resources, as long as their own values.

In comparison with the high economic and environmental cost of simply tearing down these abandoned factories, many cities around the world resort to sustainable way of dealing with them—— renovation.

\section{Introduction}

\subsection{Old Industrial Buildings.}

The old industrial building refers to those factories or architectures which have lost their original functions as buildings with time, usually remaining abandoned or idle. These buildings include buildings/structures for production, auxiliary buildings/structures for production, buildings/structures for storage, facilities and so one.

Categorized by their original function, these old buildings can be classified by light industrial buildings and heavy industrial buildings. The plants of two types are of different architectural features. The former type is less polluted and its structure is close to that of common residential and commercial buildings, which makes it the focus of old industrial building renovation in China.

These plants, like textile mill and printing plant, are usually transformed into offices, recreation and commercial venues after renovation.

\subsection{Building Renovation.}

Renovation (also called remodeling) is the process of improving a broken, damaged, or outdated structure. Renovations are typically either commercial or residential. [1] 
According to a study conducted by National Trust for Historic Preservation, renovating old buildings for higher efficiency - especially with renovations requiring fewer material inputs - have the potential to realize the greatest short-term carbon reduction [2].

Nowadays, with the rising awareness of the sustainable development, recycling of old buildings which includes old industrial buildings has become one of the main businesses of future construction business.

In Europe and America, the service of maintenance management takes up 50\% of the market share. Take U.S for example, new construction project has suffered from recession since 1970s, while maintenance and renovation has been flourishing.

\section{The Contemporary Value of Renovation of Old Industrial Buildings}

The popularity of old industrial building renovation has its contemporary values in economics, culture, history and environment, which makes it a wise choice for the government, architect and investors.

\subsection{Economic Aspects.}

Under most circumstances, the cost of renovation or rebuilding is much less than what it takes to demolish the building and construct a new one. Generally speaking, the cost of renovation is roughly $1 / 3$ to $1 / 4$ of that of demolition [3], which means a great amount of money when it comes to the construction cost.

The cost is saved in many ways. Firstly, thanks to the building material of the old building, it can be reused for new purposes. Secondly, the original structure remains so that we can make use of its foundation, maintenance structure and so on.

What's more, these plants will regain their new function as buildings after renovation, creating enormous economic benefits for the society. The reuse of once abandoned buildings and waste land resources conforms to the idea of recycling economics.

\subsection{Historical and Cultural Aspects.}

Old industrial buildings were once the architectural models of new kinds of technology, material and structure, which were an indispensable part of urban development. These architects, which is termed as "industrial heritage", carried the memory of our cities. These all contribute to the historical and cultural values of old industrial buildings.

Internationally, organizations have been established to protect industrial buildings around the world. For example, TICCIH [4], short for The International Committee for the Conservation of the Industrial Heritage and ICOMOS short for International Council on Monuments and Sites. These organizations aim to remind nations to attach importance to industrial buildings protection. Recently, China has stepped up protecting these buildings.

\subsection{Aesthetic Aspects.}

Old Industrial buildings have their own unique look or architectural styles. The old and steely look conforms to the post-modern aesthetics, creating a new aesthetic notion called "Industrial Aesthetic". This style is well welcomed by modern people especially for young people and artists, who cultivate their inspirations here.

The aesthetic value of old industrial buildings brings convenience to the renovation, which means a lot of old plants will not have to be changed in a large way.

Beijing 798, for an example, the famous and successful renovation model for old industrial buildings, remains its Bauhaus architectural style designed by German architect in 1953. Nowadays, although it lost its original function for production, the style is reserved to create a special atmosphere for creative workers and visitors.

\subsection{Environmental Aspects.}

As is mentioned above, the style of old plants is often reserved, the renovation is done in a more subtle way than rebuilding. This helps avoid lots of damage done by on-site construction to the urban environment, especially air pollution and noise pollution. 
Also, renovation has the potential to realize the greatest short-term carbon reduction as is noted in section 1.2. With the remove of polluted soil or other elements in old industrial structures for better environment for office or residence, the place becomes a cleaner place.

\section{The Renovation in HaoKe Cultural Creative Industrial Park}

In order to study the current old industrial buildings renovation in a more practical way, we chose an ordinary abandoned plant which had been renovated as a research subject in Baoding, China. Baoding is an ordinary third-tier city in China. By researching into Haoke, we can more or less see the current development situation of this industry.

\subsection{Introduction about Haoke Cultural Creative Industrial Park.}

Haoke is the first renovation architectures in Baoding, it was renovated out of an old light industrial plants located near the center of the city. In 2013, the factory complex began its renovation co-designed by a culture communication company and cultural research center of Heibei University.

This project covers an area of 60 acres, the total renovation area being 20,000 square meters. The park has seven plants, all of them are single floor factory buildings. The designers designed each plant respectively despite some major renovations they have in common.

\subsection{Major Renovation Done to the Park.}

Space Division

The typical characteristic of single floor plants is the clear height is usually very high, often reaches 7-11 meters high. Thus, how to make use of this vertical space of the plant is of critical importance in renovation.

For this type of industrial building has a really reliable load-bearing system, usually categorized into the second-class structure. Thus, we can build a two-story steel frame structure to divide the space into two floors, making full use of the vertical sphere. In this way, bigger space is made into several small areas, which convenient for working purposes.

Besides, designers also add some partitions (mobile wall, board, etc.) to add to the flexibility of space use inside the plant.

Building Material

There is another drawback about the factory, the walls are usually thin, making the temperature inside is sensitive to the outdoor temperature. In another words, these materials can neither avoid the loss of heat in winter nor insult heat in summer.

Facing this problem, architects employ some new insulation material and stick them to the wall. The common insulation materials include EPS or XPS, glass cotton pad and so one

Decoration

Decoration is an indispensable part of renovation. It helps cover some rust and perished areas and creates a new look.

Since the principle of the industrial renovation is to conform to the original industrial aesthetic style, the decoration follows the same rule. The decorating material is made "old" to fit in the ancient structure. Typically, some dry walls and old structures are remained to create a feeling of old.

\subsection{Remaining Problems.}

The renovation of Haoke is generally a success one, attracting dozens of cultural enterprises and creative individuals from all over the city, which makes Haoke the art center of Baoding. However, after we surveyed the tenants in the park, we still found out some inconveniences during their working.

Insufficient Power supply

According to our survey, the tenants will have to gather in one room in their working area when the winter comes, because the power of the park can not afford every air conditioner in one unit. They face the same situation in summer.

What's more, the price of the electricity price is really high in industrial area. Thus, energy problems is remained to be solved in the park.

Inadequate Green Areas 
As is like other renovated industrial buildings, Haoke is renovated as each unit, not as the whole. The green rate of the whole factory district is really low, failing to embrace the concept of ecological.

\section{Conclusion}

Renovation is now widely employed by different countries to make use of these old buildings. Thanks to the historical and cultural values carried by these buildings, renovation can be carried out with original architectural style, which makes the remodeling process a lot easier and cheaper than building a new construction.

With the example of Haoke cultural creative industrial park, we can see clearly what is happening in the second-tier cities in China. The renovations surely do well to the local government, enterprises and parties involved. Except from economic benefits, the reservation of old factories sustains the industrial memories of the cities. However, as is revealed by the example, there still remain many problems in remodeling. Owing to the limitation of current building technology, some of the intrinsic drawbacks of industrial plants still exist, causing inconvenience to working and residence.

Although, still, there is a long way to go in this industry, the renovation of old industrial buildings is an irresistible trend of the time, no matter economically or culturally speaking.

\section{References}

[1] Information on https://en.wikipedia.org/wiki/Renovation

[2] Information on www.buildings.com “New Construction vs. Renovation: Which is Greener?”

[3] Rong ge, Landscape activation and regeneration of industrial plant waste---Shanghai M50 pairs Kunming Jinding 1919 Reference and Exploration ([D],kunming university of science and technology,China,2013)p.10

[4] Information on http://ticcih.org/ 